\section{National standards for}

\section{forensic pathology training}

\section{slow to develop}

A groundbreaking review of autopsies performed by a former Ontario pathologist has sparked a national debate about the training and accreditation of the medical professionals who investigate criminally suspicious deaths and homicides.

In April, Ontario ordered a full public inquiry into the work of Dr. Charles Smith, formerly the head of the pediatric forensic pathology unit at Toronto's Hospital for Sick Children. A review of Smith's cases by a team of international experts uncovered mistakes in 20 of the autopsies he performed, I3 of which resulted in criminal convictions.

In the wake of those shocking results, it has since been revealed that medical professionals with no formal training in forensic pathology perform many of the legal autopsies introduced as evidence in courtrooms across Canada. For that reason, there are many who believe there will soon be a flood of similar reviews and a whole lot of criminal cases being re-opened.

"It's certainly the tip of the iceberg," says Dr. John Butt, a renowned forensic pathologist who sat on the panel that assessed Smith's work. "By the time the Smith cases are finished, I think we'll see this kind of review across the country."

Unlike the United States and United Kingdom, Canada's medical community has been entirely unable to reach a consensus on national standards for post-graduate training in forensic pathology, Butt says. As a result, anatomic or general pathologists are called upon to perform legal autopsies in larger communities, while in smaller communities it is not unusual to have physicians on a part-time basis conduct these critical examinations.

"We just haven't asked ourselves, what is the training of the person who performs that work?" Butt adds. "If that person is not properly trained, or is only doing it part time, then you're not going to get the result you need."

Dr. Andrew Padmos, chief executive officer of the Royal College of Physicians and Surgeons, says the medical community had largely accepted the notion that there needs to be specific training for forensic pathologists before the Smith scandal broke in Ontario.

The College added forensic pathology as a subspecialty in 2003 , and hopes to issue formal standards for a I-year, post-graduate training program by the summer of 2008, Padmos says. But it remains unclear how many medical schools will be ready to offer specific courses in forensic pathology.

Padmos expects a handful of schools - including those at the University of Toronto, University of Manitoba and the University of British Columbia - to be among the first to offer post-graduate training in forensic pathology.

He concedes, however, that it could take many years to replace the general and anatomic pathologists now conducting legal autopsies with pathologists who have specific forensic training. "It's always a little scary at the beginning of a training program to find the trainees and the faculty," Padmos says. "It's a low-volume specialty right now and it's likely that only a very few medical students will be drawn to it."

The controversial Smith graduated from the University of Saskatchewan medical school in 1975 and was hired as a surgeon by the Hospital for Sick Children in 1979. Within a year, he undertook training as an anatomic pathologist and in $198 \mathrm{I}$, began performing autopsies on children, focusing on those who died by accidental or natural causes. Despite having no formal training in forensic pathology, within a few years he was performing autopsies in cases of unexplained death and homicide. By the late I9gos, he was considered Canada's most consulted and cited pathologist.

Along with the notoriety, however, came a flood of complaints about his

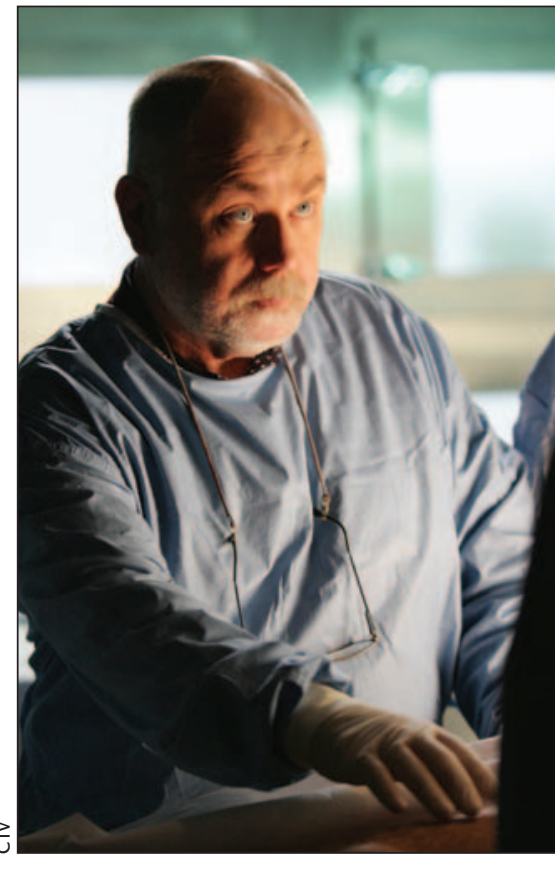

Actor Robert David Hall has become the archetype for all coroners for his work on the television drama series CSI: Crime Scene Investigation, in which he plays the droll Dr. Al Robbins and gets to deliver such memorable lines as "urine ... you're out," after drawing a sample from a cadaver's bladder. The 59-year-old has also become a prominent voice for the disabled. He was equipped with prosthetics after having both legs amputated and suffering burns over $65 \%$ of his body when his car was crushed by an 18-wheeler in 1978.

work. Concerns about his work first arose in I99I after a judge rebuked him for not considering other causes in a shaken baby case. In 200I, Smith's work was formally reviewed by the Ontario chief coroner's office, which declared the embattled pathologist competent. The details of that review were never made public.

In 2002, after receiving several complaints about his work in criminal cases, the Ontario College of Physicians and Surgeons investigated and cautioned Smith for being "overly dogmatic" and having a "tendency towards overstatement." A second review of 
Smith's work began in 2005, when Ontario Chief Coroner Barry McLellan struck an international panel of experts to review 45 legal autopsies performed by Smith over a ro-year period commencing in I99I.

The review, released last April, confirmed the worst fears about Smith's work. A panel of 5 forensic pathologists found mistakes had been made in 20 of the 45 cases reviewed. Premier Dalton McGuinty immediately signaled he would call a public inquiry.

Advocates for the wrongly convicted are demanding major reforms to the accrediting procedures for pathologists and the rules under which they give testimony. The Association in Defense of the Wrongly Convicted, which represents several of the men and women convicted in part on Smith's evidence, says it is difficult to estimate the number of potential miscarriages of justice caused by inadequately trained pathologists.

Association lawyer James Lockyer represents William Mullins-Johnson, who spent 12 years in prison for the I993 murder of his 4-year-old niece, who Smith concluded had been sodomized and strangled. Other forensic experts subsequently concluded the girl died of natural causes.

In addition to specific training and accreditation, Lockyer argues that pathologists should be instructed on how to present evidence objectively and how to manage their relationship with police and prosecutors. As was the case with other scientific experts - such as hair and fibre microscopists - pathologists can be made to feel they are part of the prosecution "team" and that they must tailor evidence to help secure a conviction, he adds.

The criminal justice system must also provide the resources to allow accused people to call their own forensic experts to balance the opinions of those employed directly by the state, Lockyer says. "Clearly, like any group that regularly works for government, they are going to suffer from cultural problems. I have always favoured separating [scientific experts and prosecution services] as much as you can." Dan Lett, Winnipeg

DOI:I0.I503/cmaj.07088I

\section{Bernstein bails presidency}

W

eary of serving as the "scapegoat" for researchers who are disgruntled about declining success rates in grant competitions, Canadian Institutes of Health Research (CIHR) President Dr. Alan Bernstein will walk away from the final 3 years of his second term by resigning his post effective Oct. 3 I.

"You don't want to overstay your welcome," said Bernstein, who has been at the CIHR helm for 7 years. "In these leadership positions, you have to be careful to leave at the right time and the longer you are on the job, the more defensive you get of your own track record."

The basic biomedical research community has simmered with discontent as success rates in grant competitions began to drop as a consequence of the federal government having contained the growth rate of the agency's base budget to $5 \%$ or less in each of the past 3 years.

Complaints were few as the overall CIHR pie grew rapidly at the start of the decade from a $\$ 250$ million level in 200I, when the predecessor Medical Research Council was dissolved in favor of an agency with a mandate to expand the ambit of Canadian research beyond basic biomedical science to include 3 other pillars: clinical, population health, and health services and systems research.

But as the CIHR received modest budget increases of $4.4 \%, 2.4 \%$ and $5 \%$, respectively, in the past 3 years (raising the current base budget to $\$ 737$ million), the biomedical research community began grumbling about the extent to which monies were being funneled into the 3 other pillars or being pumped into strategic initiatives in areas of national health need. A review of CIHR's structure, function and processes conducted last year indicated the community wanted to clip the wings of senior management by decentralizing authority to divide the financial pie (CMAJ 2006; I75[8]:857-8). The governing council subsequently agreed to establish such a decision-making committee, comprised primarily of the scientific directors of CIHR's existing I 3 institutes.

It's only natural for such complaints to surface as budgetary pressures increase, Bernstein said. "They want to

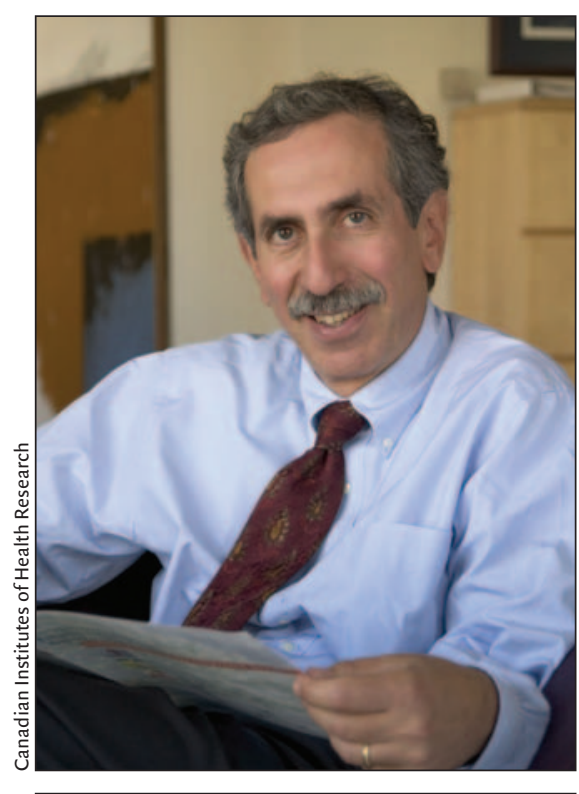

"I've accomplished what I set out to do," CIHR President Dr. Alan Bernstein says while announcing his resignation.

find a scapegoat. That's why I'm paid the big bucks."

There are those within the research community who don't understand that the CIHR has a mandated, legislative responsibility to significantly expand the ambit of its research, as that was the rationale for its creation, Bernstein added. "Some people have difficulty seeing that vision. Fair enough. But that's not CIHR. CIHR has a broader vision."

Bernstein also indicated that his resignation should not be construed as an expression of dissatisfaction with the government's plans to separate the presidency into 2 administrative positions, while appointing more corporate representatives to the governing board (CMAJ 2007;177[I]:2I-2). "I never felt it was a top ro priority in terms of a science and technology policy but I don't object to that." Nor did the government quietly orchestrate his departure. "I've never felt nudged."

Bernstein will not return to the Samuel Lunenfeld Institute, where he earned his scientific stripes through stem cell research. Rather, he'll pursue international career options. "I just turned 60 and I felt I've got another job in me. But I'm not sure what it'll be yet." - Wayne Kondro, CMAJ

DOI:Io.I503/cmaj.0709I4 